\title{
Effect of lysosomal and ubiquitin-proteasome system dysfunction on the abnormal aggregation of $\alpha$-synuclein in PC12 cells
}

\author{
RUNQING WANG $^{1}$, JIE ZHAO ${ }^{1}$, JIEWEN ZHANG ${ }^{2}$, WEI LIU $^{1}$, MEIYING ZHAO ${ }^{1}$, \\ JIANGTAO LI ${ }^{1}$, JUAN LV ${ }^{1}$ and YANAN LI ${ }^{1}$ \\ ${ }^{1}$ Department of Neurology, Zhengzhou Central Hospital Affiliated to Zhengzhou University, Zhengzhou, Henan 450007; \\ ${ }^{2}$ Department of Neurology, Henan Provincial People's Hospital, Zhengzhou, Henan 450003, P.R. China
}

Received June 22, 2014; Accepted March 16, 2015

DOI: $10.3892 /$ etm.2015.2432

\begin{abstract}
The aim of this study was to investigate the effect of lysosomal and ubiquitin-proteasome system dysfunction on the abnormal aggregation of $\alpha$-synuclein, and to analyze its role in the pathogenesis of Parkinson's disease (PD). PC12 cells subjected to nerve growth factor-induced differentiation were used as the cell model to study the dopaminergic neurons, and the lysosomal and proteasomal inhibitors trans-epoxysuccinyl-L-leucylamido-(4-guanidino) butane (E64) and, respectively, were used exclusively and in combination to treat the PC12 cells. The viability and metabolic state of the cells was assessed using the MTT assay; flow cytometry was used to measure the rate of cell apoptosis; and the double immunofluorescence method was applied to observe the formation of thioflavin $S$ - and $\alpha$-synuclein protein-positive aggregates and inclusion bodies in the PC12 cells. In addition, the Hoechst 33258 staining method was used to observe the apoptosis of the $\alpha$-synuclein protein and thioflavin-S double-labeled cells. Following the administration of the lysosomal and proteasomal pathway inhibitors, the cell viability decreased in a concentration-dependent manner and the cell apoptosis rate increased. The proportion of PC12 cells with $\alpha$-synuclein protein-positive aggregates and inclusion bodies in the E64 group was 7.94\%, compared with 20.33 and $36.77 \%$ in the lactacystin and combination treatment groups, respectively. Statistical analysis indicated that the number of inclusion body-positive cells in the treatment groups was significantly higher than that in the control group $(3.78 \%)(\mathrm{P}<0.05)$. Apoptosis was evident in the double-positive cells with $\alpha$-synuclein protein-positive inclusion bodies $(17.29 \pm 1.54 \%)$. In conclusion, lysosomal and proteasomal dysfunction may play an important role in the pathogenesis
\end{abstract}

Correspondence to: Dr Jie Zhao, Department of Neurology, Zhengzhou Central Hospital Affiliated to Zhengzhou University, 195 Tongbai Road, Zhengzhou, Henan 450007, P.R. China

E-mail: jiezhaocn@163.com

Key words: lysosomes, ubiquitin-proteasome, PC12 cell, $\alpha$-synuclein of PD through the induction of abnormal $\alpha$-synuclein protein aggregation in dopaminergic neurons.

\section{Introduction}

Parkinson's disease (PD) is a common degenerative disease in the nervous system. The neuropathological characteristics of the disease include the progressive pallidal degeneration of dopaminergic neurons in the pars compacta of the substantia nigra, and the formation of intracellular inclusion bodies known as Lewy bodies (LBs) (1). It is believed that the nerve cell death in PD is induced by the change in the protein conformation of $\alpha$-synuclein to form amyloid filaments, resulting in abnormal aggregation (2-5). Furthermore, studies of transgenic mice and Drosophila models have demonstrated that the formation of $\alpha$-synuclein inclusion bodies is associated with the degeneration of the nervous system $(6,7)$, and that proteasomal dysfunction may cause the formation of the $\alpha$-synuclein protein aggregates and inclusion bodies. The proteasomal inhibitor lactacystin has been shown to be able to induce the death of PC12 cells and the formation of cell inclusion bodies (8). Previous studies have demonstrated that systematic drug administration can result in behavioral changes similar to those of PD in mice; furthermore, the damage to the central nervous system is strikingly similar to that in patients with PD $(9,10)$.

Protein degradation in the cell can also occur through the lysosomal pathway; however, few studies have investigated the association between the lysosomal pathway and PD, the effect of the lysosomal and ubiquitin-proteasome pathways on $\alpha$-synuclein protein degradation or the correlation between the pathways. The aim of the present study, therefore, was to observe the effect of the lysosomal and proteasomal inhibitors trans-epoxysuccinyl-L-leucylamido-(4-guanidino) butane (E64) and lactacystin, respectively, on $\alpha$-synuclein protein degradation, and to explore the effect of lysosomal pathway degradation on proteasomal pathway degradation. Furthermore, the apoptotic status of the inclusion body-positive cells was evaluated in order to elucidate the association between the inhibition of the lysosomal and proteasomal pathways and the death of dopaminergic neurons, and to provide an experimental and theoretical foundation for the pathogenesis of PD. 


\section{Materials and methods}

Cell culture. In this study, a rat pheochromocytoma cell line (PC12) was provided by the China Center for Type Culture Collection (Wuhan University, Wuhan, China). The cells were placed into Dulbecco's modified Eagle's medium (Gibco-BRL, Grand Island, NY, USA) containing 10\% inactivated calf serum (Gibco-BRL), 5\% horse serum (Gibco-BRL), penicillin $(100 \mathrm{U} / \mathrm{ml})$ and streptomycin $(100 \mathrm{U} / \mathrm{ml})$, and cultured in a Forma $^{\mathrm{TM}} \mathrm{CO}_{2}$ cell incubator (3195/N; Thermo Fisher Scientific Inc., Waltham, MA, USA) with $5 \% \mathrm{CO}_{2}$ and at $37^{\circ} \mathrm{C}$. The culture medium was renewed every two days. Nerve growth factor (NGF; BeiDaZhiLu Biological Engineering Co., Ltd., Xiamen, China) at a final concentration of $50 \mathrm{ng} / \mathrm{ml}$ was used to induce the neuronal differentiation of the PC12 cells one week prior to the drug treatment, and the morphological changes prior and subsequent to the PC12 cell induction were observed using an inverted phase contrast microscope (Olympus Corp., Tokyo, Japan). On the day of medication, lactacystin and E64 (Sigma-Aldrich) were added to 1 and $10 \mathrm{mmol} / \mathrm{l}$ culture medium, respectively. The final concentrations of lactacystin were 5, 10 and $20 \mu \mathrm{mol} / \mathrm{l}$, while those of E64 were and 2, 20 and $200 \mu \mathrm{mol} / 1$.

MTT assay. The PC12 cell density was regulated to $2 \times 10^{5} / \mathrm{ml}$, and the cells were inoculated into a 96 -well tissue culture plate with $100 \mu \mathrm{l}$ in each well. After $24 \mathrm{~h}$, different concentrations of lactacystin $(5,10$ and $20 \mu \mathrm{mol} / \mathrm{l}), \mathrm{E} 64(2,20$ and $200 \mu \mathrm{mol} / \mathrm{l})$ and lactacystin plus E64 (5+2, 10+20 and 20+200 $\mu \mathrm{mol} / \mathrm{l})$ were added, respectively, and left to react for $24 \mathrm{~h}$. Six wells were assigned to each treatment, and parallel control wells without treatment reagent were also established. A total of $10 \mu \mathrm{l}$ MTT (5 mg/l) (Sigma-Aldrich, St. Louis, MO, USA) was added to each well after $24 \mathrm{~h}$, and the cells were cultured for an additional $4 \mathrm{~h}$. The culture medium was subsequently removed and $100 \mu \mathrm{l}$ dimethyl sulfoxide (Sigma-Aldrich) was added to each well and mixed through oscillation. A microplate reader (Bio-Rad, Hercules, CA, USA) was used to test the optical density (OD) value of each well at a wavelength of $570 \mathrm{~nm}$. The $\mathrm{A}_{570} \mathrm{OD}$ value was considered to represent the viability of the PC1 2 cells. All experiments were repeated at least three times.

Phospholipid binding protein (Annexin-V)-propidium iodide (PI) double-staining method. The PC12 cells were treated with lactacystin $(20 \mu \mathrm{mol} / 1)$, E64 (200 $\mu \mathrm{mol} / \mathrm{l})$ and lactacystin plus E64 $(20+200 \mu \mathrm{mol} / \mathrm{l})$, respectively, for $24 \mathrm{~h}$, prior to being collected and digested with $0.14 \mathrm{~g} / 1$ EDTA. The cells were then washed with precooled phosphate-buffered saline (PBS) at $4^{\circ} \mathrm{C}$ to generate a single cell suspension. The cell density was adjusted to $5 \times 10^{5} / \mathrm{ml}$, and then $100 \mu \mathrm{l}$ cell suspension was removed and supplemented with $5 \mu \mathrm{l}$ Annexin-V/fluorescein isothiocyanate (FITC) and $10 \mu \mathrm{l}$ PI at $20 \mu \mathrm{g} / \mathrm{ml}$. PBS $(400 \mu \mathrm{l})$ was added after $15 \mathrm{~min}$ incubation in the dark at room temperature, and the fluorescence intensity and rates of early cell apoptosis were detected via flow cytometry using the FACSCalibur ${ }^{\mathrm{TM}}$ system (BD Biosciences, Franklin Lakes, NJ, USA).

Immunofluorescence method. The PC12 cells were inoculated into a 24-well tissue culture plate with cover glass
(poly-L-lysine pretreatment). When the cells reached the logarithmic growth phase, lactacystin $(20 \mu \mathrm{mol} / 1)$, E64 $(200 \mu \mathrm{mol} / \mathrm{l})$ and lactacystin plus E64 $(20+200 \mu \mathrm{mol} / \mathrm{l})$ were added, respectively, and a control group was additionally established. After $24 \mathrm{~h}$ of incubation, the PC12 cells were immobilized by ice-cold acetone/absolute ethyl alcohol (1:1) for $10 \mathrm{~min} ; 2 \%$ Triton X-100-PBS was then added at room temperature for $20 \mathrm{~min}$ and the cells were incubated with $0.1 \%$ thioflavin $\mathrm{S}$ for a further $10 \mathrm{~min}$. Following incubation, the cells were transferred to $80 \%$ alcohol for differentiation for $5 \mathrm{~min}$, oscillated and washed. Bovine serum albumin (3\%) was added for an additional $30 \mathrm{~min}$ of incubation at room temperature, excess liquid was extracted and goat polyclonal anti-rat $\alpha$-synuclein protein antibody $(1: 100$; sc-7012; Santa Cruz Biotechnology, Inc., Santa-Cruz, CA, USA) was added for incubation at $4^{\circ} \mathrm{C}$ for $24 \mathrm{~h}$. In the negative control group, the goat anti-rat $\alpha$-synuclein protein antibody was replaced by PBS. Following incubation with the primary antibody, tetramethylrhodamineisothiocyanate (TRITC; Beijing Zhongshan Golden Bridge Biotechnology Co., Ltd., Beijing, China)-labeled rabbit anti-goat fluorescent secondary antibody (1:100; Santa Cruz Biotechnology, Inc.) was added and incubated for $90 \mathrm{~min}$ at room temperature. A total of $500 \mu \mathrm{l}$ Hoechst 33258 stain $(2 \mu \mathrm{g} / \mathrm{ml})$ was added to each well, and the cells were incubated in the dark for $15 \mathrm{~min}$ at room temperature to facilitate the development of the double-staining of the cell nucleus. The PC12 cells were then washed three times with PBS for 5 min each time. A fluorescence microscope and Image-J (version $1.43 \mathrm{~h}$ ) image processing system (Olympus Corp., Tokyo, Japan) were utilized to observe the formation of $\alpha$-synuclein protein- and thioflavin S-positive inclusion bodies within the cytoplasm and the morphological variations in the nuclear chromatin during apoptosis. Each treatment had four wells and each experiment was repeated three times.

Statistical analysis. SPSS software, version 16.0 (SPSS Inc., Chicago, IL, USA) was used to perform the statistical analysis. All data are expressed as the mean \pm standard deviation. Comparisons of the data between each treatment group and the control group were conducted through the t-test or rank sum test. A homogeneity of variance test was implemented prior to the comparison of different groups; analysis of variance was applied when homogeneity was observed, while the rank sum test was applied when there was no homogeneity. The Student-Newman-Keuls method was applied to compare the difference between each group, and $\mathrm{P}<005$ was considered to indicate a statistically significant difference.

\section{Results}

Morphological changes prior and subsequent to the NGF induction. As shown in Fig. 1, the PC12 cells had a regular shape (circular or oval) prior to the induction, with each cell exhibiting few bulges and a short length. Intercellular connections were rare. Following the induction, the cells became irregularly shaped, with a polygonal or spindle outline. In addition, more bulges appeared, the cells became longer and intercellular connections became more common. 
Table I. Rates of apoptosis and necrosis following the treatment of PC12 cells with lactacystin, E64 and lactacystin plus E64, respectively, for $24 \mathrm{~h}$.

\begin{tabular}{lcccccc}
\hline Group & Apoptotic cell death $(\%)$ & t-value & P-value & Necrotic cell death (\%) & t-value & P-value \\
\hline Lactacystin & $38.09 \pm 1.71$ & 10.34 & $<0.01$ & $1.78 \pm 0.46$ & 0.97 & $>0.05$ \\
E64 & $29.05 \pm 0.77$ & 8.72 & $<0.01$ & $6.76 \pm 0.51$ & 6.39 & $<0.01$ \\
Lactacystin + E64 & $44.36 \pm 1.19$ & 12.03 & $<0.01$ & $7.15 \pm 0.87$ & 7.03 & $<0.01$ \\
Control & $0.79 \pm 0.55$ & - & - & $1.01 \pm 0.36$ & - & - \\
\hline
\end{tabular}

Results are presented as the mean \pm standard deviation; $\mathrm{n}=18$. E64, trans-epoxysuccinyl-L-leucylamido-(4-guanidino) butane.
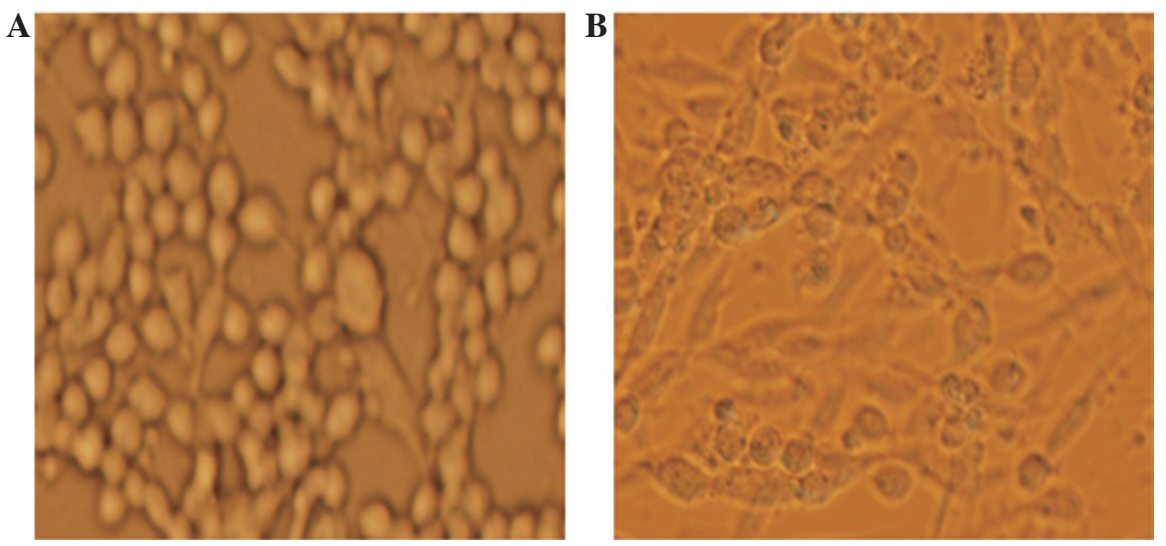

Figure 1. Morphological changes (A) prior and (B) subsequent to the nerve growth factor induction in PC12 cells (magnification, x100).

Effect of lactacystin and E64 on the activity and metabolic status of the cells. The $\mathrm{A}_{570}$ value of the control group was $0.618 \pm 0.055$. As the lactacystin was administered in increasing concentrations, the viability of the cells decreased steadily, exhibiting a dose-response association (Fig. 2). An evident dose-response association was also observed for E64, with the viability of the cells decreasing markedly following the administration of increasing concentrations of E64. Notably, the OD values of the lactacystin plus E64 treatment groups showed more marked reductions than those in the lactacystin or E64 groups, indicating that the viability of the cells in the lactacystin plus E64 treatment groups had decreased considerably.

Statistical analysis showed that the differences in the OD values at each concentration between the lactacystin and lactacystin plus E64 groups, as well as between the E64 and lactacystin plus E64 groups, were significant $(\mathrm{P}<0.05)$, with the exception of the comparison between the $5 \mu \mathrm{mol} / 1$ lactacystin and the $5 \mu \mathrm{mol} / 1$ lactacystin plus $2 \mu \mathrm{mol} / 1 \mathrm{E} 64$ groups $(\mathrm{P}>0.05)$. In comparison with the $\mathrm{OD}$ values of the control group, significant differences were found in the values of the lactacystin, E64 and lactacystin plus E64 groups at all concentrations $(\mathrm{P}<0.05)$, with the exception of the comparison between the OD values of the $2 \mu \mathrm{mol} / 1 \mathrm{E} 64$ and control groups $(\mathrm{P}>0.05)$.

Effect of lactacystin, E64 and lactacystin plus E64 on apoptosis and necrosis in the PC12 cells. Live cells exhibited no FITC and PI staining (FITC- PI $^{-}$), as shown by the lower-left cell cluster in the analysis charts. Apoptotic cells were negative

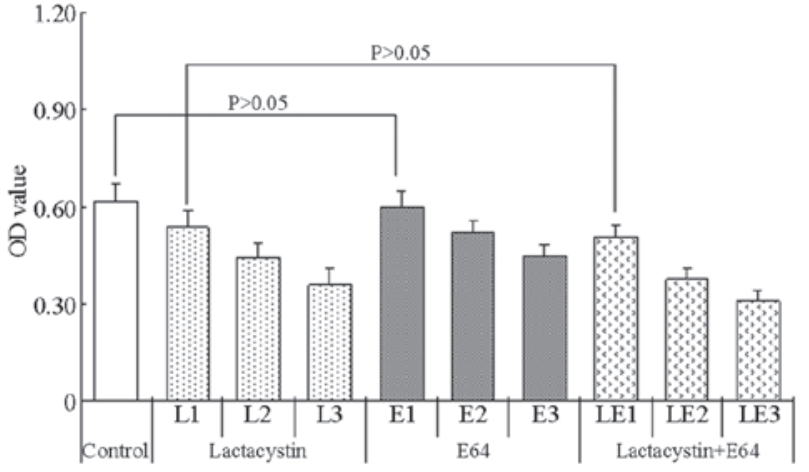

Figure 2. Viability of PC12 cells after $4 \mathrm{~h}$ of MTT treatment and the administration of pathway inhibitors at different concentrations. The cells were divided into the lactacystin (concentrations for L1, L2 and L3 were 5, 10 and $20 \mu \mathrm{mol} / 1$, respectively), E64 (concentrations for E1, E2 and E3 were 2, 20 and $200 \mu \mathrm{mol} / 1$, respectively) and lactacystin plus E64 (concentrations for LE1, LE2 and LE3 were 5+2, 10+20, 20+200 $\mu \mathrm{mol} / 1$, respectively) groups. Results are presented as the mean \pm standard deviation. OD, optical density; E64, trans-epoxysuccinyl-L-leucylamido-(4-guanidino) butane.

for PI and highly stained by FITC $\left(\mathrm{FITC}^{+}, \mathrm{PI}^{-}\right)$, as shown by the lower-right cell cluster in the analysis charts. Necrotic cells were highly stained by PI and FITC $\left(\mathrm{FITC}^{+}, \mathrm{PI}^{+}\right)$, as shown by the upper-right cell cluster in the analysis charts (Table I and Fig. 3).

Rates of $\alpha$-synuclein protein and thioflavin $S$ double-stained cells and apoptosis in the double-stained cells after $24 \mathrm{~h}$ of lactacystin, E64 and lactacystin plus E64 treatment in PC12 

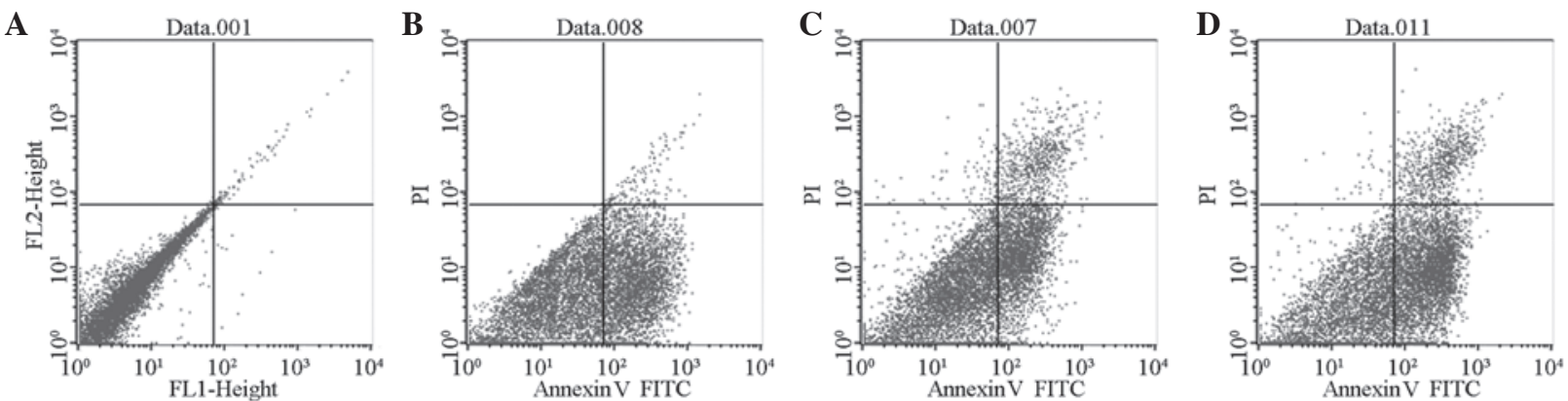

Figure 3. Distribution of apoptotic and necrotic cells following the treatment of PC12 cells with lactacystin, E64 and lactacystin plus E64 for $24 \mathrm{~h}$, as assessed through flow cytometry. (A) Control, (B) lactacystin, (C) E64 and (D) lactacystin plus E64. E64, trans-epoxysuccinyl-L-leucylamido-(4-guanidino) butane; FITC, fluorescein isothiocyanate; PI, prodidium iodide.

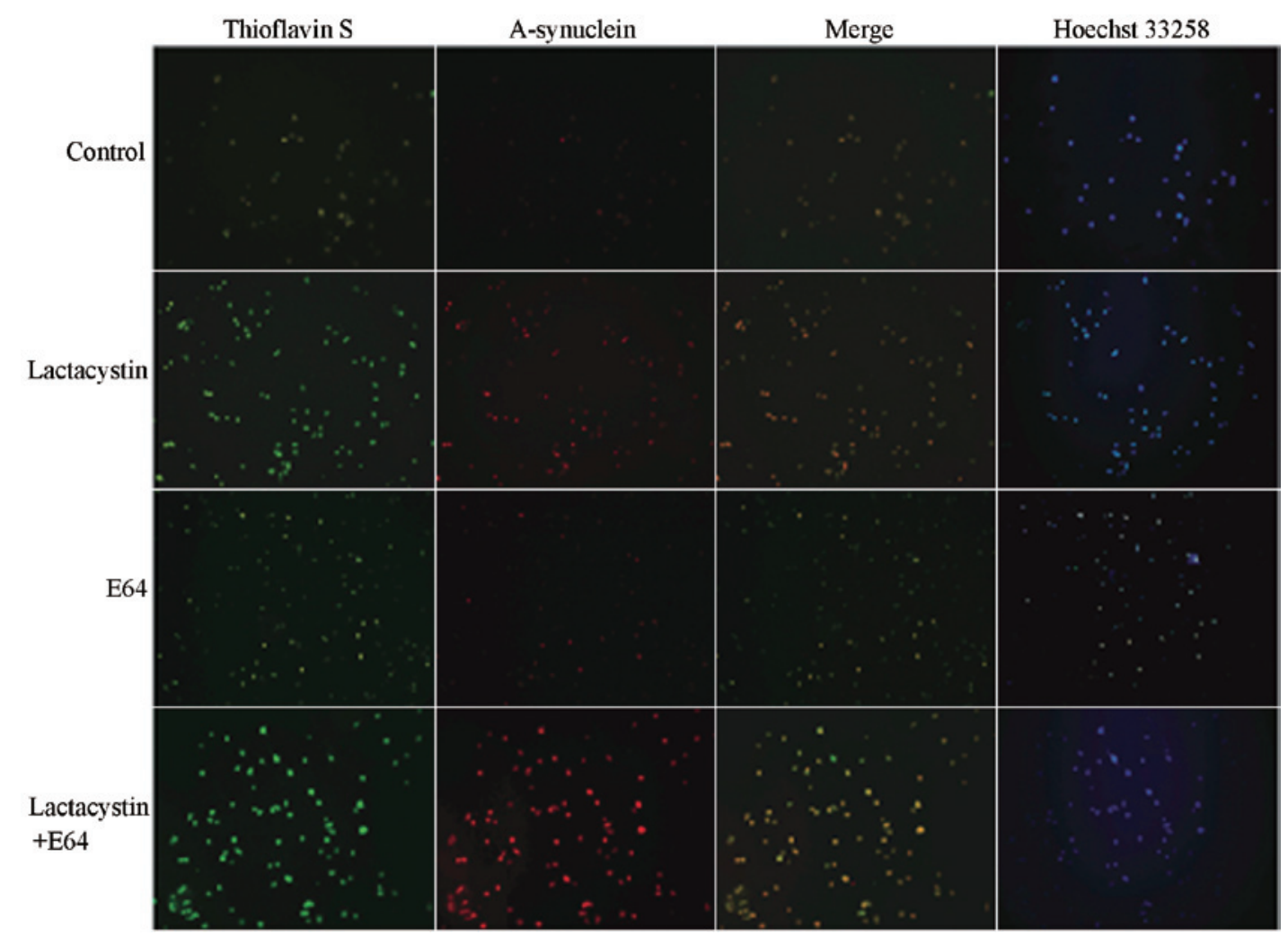

Figure 4. Immunofluorescent images of PC12 cells stained by thioflavin S, $\alpha$-synuclein, merge and Hoechst 33258, respectively, after $24 \mathrm{~h}$ of treatment with lactacystin, E64 and lactacystin plus E64 (magnification, x100). E64, trans-epoxysuccinyl-L-leucylamido-(4-guanidino) butane.

cells. In the control group, few PC12 cells exhibited $\alpha$-synuclein protein and thioflavin $\mathrm{S}$ double-positive inclusion bodies $(3.78 \pm 0.40 \%)$. After $24 \mathrm{~h}$ of $20 \mu \mathrm{mol} / 1$ lactacystin treatment, however, the number of cells that were positive for inclusion bodies was increased to $20.33 \pm 2.4 \%$; after $24 \mathrm{~h}$ of $200 \mu \mathrm{mol} / 1$ E64 treatment, the number of inclusion body-positive cells was also increased (7.94 \pm 0.97$)$. The greatest increase in the number of inclusion body-positive cells was observed in the lactacystin plus E64 treatment group (36.77 $\pm 3.5 \%)$. Comparisons with the control group showed that the differences were all significant $(\mathrm{P}<0.05)$ (Table II).

Thioflavin S staining is used to indicate the presence of amyloids; the protein in its normal state or small protein aggregates cannot undergo combination with thioflavin S (11). When the protein conformation changes, large clumps can combine with thioflavin $\mathrm{S}$, and the combined complex can be stimulated to emit green fluorescence under the blue light of the fluorescence microscope. By comparison, the $\alpha$-synuclein that has combined with the TRITC can emit red fluorescence under the fluorescence microscope. Fig. 4 shows the staining as observed under the fluorescence microscope. Where double-staining of $\alpha$-synuclein protein and thioflavin $\mathrm{S}$ occurred, the PC12 cells appeared yellow or orange. The nuclei of normal cells stained by Hoechst 33258 appeared even and hazy blue, while in the apoptotic cells, the chromatin appeared in clusters, the size of particles was different and the blue was brighter; these cells therefore exhibited that the morphological characteristics of chromosome condensation. The microscopic observations indicated that the double-positive cells showed an apoptotic tendency $(17.29 \pm 1.54 \%)$; however, the differences in the apoptotic states between the control and treatment groups were not significant $(\mathrm{P}>0.05)$. 
Table II. Rates of $\alpha$-synuclein protein and thioflavin $\mathrm{S}$ double-stained cells and apoptosis in the double-stained cells after $24 \mathrm{~h}$ of lactacystin, E64 and lactacystin plus E64 treatment, respectively, in PC12 cells.

\begin{tabular}{lcc}
\hline Group & Inclusion-harboring cells $(\%)$ & Apoptotic inclusion-harboring cells (\%) \\
\hline Lactacystin & $20.33 \pm 2.40^{\mathrm{a}}$ & $16.42 \pm 4.46$ \\
E64 & $7.94 \pm 0.97^{\mathrm{a}}$ & $18.75 \pm 4.42$ \\
Lactacystin + E64 & $36.77 \pm 3.50^{\mathrm{a}, \mathrm{b}}$ & $18.33 \pm 6.04$ \\
Control & $3.78 \pm 0.40$ & $16.67 \pm 5.56$ \\
\hline
\end{tabular}

${ }^{\mathrm{a} C}$ Compared with the control group, $\mathrm{P}<0.05$; ${ }^{\mathrm{b}}$ compared with the lactacystin and E64 groups, $\mathrm{P}<0.01$. No significant difference in apoptosis rate was found among the groups $(\mathrm{P}>0.05)$. The cell population of each group was $1 \times 10^{5} / \mathrm{ml}$. E64, trans-epoxysuccinyl-L-leucylamido-(4-guanidino) butane.

\section{Discussion}

In 1988, Maroteaux et al (12) isolated a 143-amino acid protein from Torpedo electric organ cholinergic nerve terminals and named it synuclein. Following the discovery of synuclein came the identification of its protein homologs, and synuclein was renamed $\alpha$-synuclein (13). At the end of the 20th century, it was found that certain patients with familial PD exhibited an $\alpha$-synuclein gene mutation, which incited interest into the study of $\alpha$-synuclein (5). It has subsequently been found that, whether in familial or sporadic PD, the aggregation of abnormal $\alpha$-synuclein forms LBs and that this abnormal $\alpha$-synuclein aggregation in the neurons of the substantia nigra constitutes a pathological morphological marker for PD (14).

In normal conditions, $\alpha$-synuclein has an unordered and unfolded structure; however, under high concentrations or conditions conducive to abnormal modifications the protein undergoes a conformational change into fibers rich in $\beta$-sheets, which form oligomers and exhibit cytotoxicity $(15,16)$. Since it is believed that $\alpha$-synuclein aggregation could play an important role in the occurrence and development of PD, it is crucial to elucidate the mechanism underling the $\alpha$-synuclein aggregation in cells in order to facilitate the understanding of PD pathogenesis.

There are two principal pathways of cellular protein degradation: The ubiquitin-proteasome pathway and the lysosomal pathway (17). The ubiquitin-proteasome pathway involves substrate ubiquitination and is an orderly process mediated by a series of enzymes. Ubiquitin is first activated by the ubiquitin-activating enzyme E1, and then transferred directly to the ubiquitin-carrier enzyme $\mathrm{E} 2$, which acts to conjugate ubiquitin to the $\varepsilon$-amino group of the lysine residues in the substrate protein. E2 can ubiquitinate the substrate directly or in conjunction with a ubiquitin ligase. In this way, through a cascade of enzymatic reactions, ubiquitin $\mathrm{C}$-terminal glycine residues covalently bond with the $\varepsilon$-amino group of the lysine residues in the target protein. The ubiquitin molecules can then form a polyubiquitin chain via the connection of lysine 48 residues, and this polyubiquitin chain is the activated signal of protein degradation, which can be identified and degraded by the $26 \mathrm{~S}$ proteasome. The ubiquitin and proteasome-mediated degradation of specific proteins in cells underlies cell adjustment in processes such as the cell cycle, cell apoptosis, pinocytosis, immunization and the inflammatory reaction. At present, it is believed that in certain harmful environments, such as under conditions of oxidative or endoplasmic reticulum stress and in protein misfolding in the ageing process, damaging abnormal protein aggregation can be found in the cell. This abnormal protein aggregation is initiated as a result of modifications in protein synthesis, abnormal protein cleavage and the decreased capacity of the cell to deal with the abnormal protein expression, and ultimately leads to cell dysfunction or death (18).

Lysosomes are dynamic organelles that are surrounded by a single membrane, often present as a cycle and contain electron-dense material (19). Lysosomes contain $>50$ species of hydrolase in an acid environment, and acid phosphatase is the marker enzyme, which controls the degradation of intracellular macromolecules, including protein, lipid and cytoplasmic organelles. Lysosomes are known as the cellular alimentary organs. According to the different stages of physiological function, lysosomes can be divided into primary and secondary lysosomes and residual bodies. It is generally believed that proteins with a long half-life can be degraded by lysosomes. In addition to acting as the alimentary organs in the cell, lysosomes are associated with autocytolysis, cytophylaxis and the usage of certain substances, such as antibodies and hormones. Lysosomes degrade intracellular protein via the autophagy mechanism. There are at least three different types of autophagy: Macroautophagy, microautophagy and chaperone-mediated autophagy (CMA). In macroautophagy, the soluble proteins and damaged organelles within the cytoplasm are bundled into a double-membrane structure of non-lysosomal origin, which is known as an autophagosome; the autophagosome then brings the proteins to the lysosome for degradation. Microautophagy differs from macroautophagy in that the cytoplasmic substrates are directly engulfed by the lysosome via the deformation of the lysosomal membrane. By contrast, the process of CMA is selective for certain proteins; these are transferred to the lysosomal membrane and then translocated into the lysosomal lumen for hydrolase-mediated degradation.

Webb et al (20) found that $\alpha$-synuclein protein could undergo degradation via two pathways: Proteasomal and lysosomal. A previous study demonstrated that there is a molecular switch in the body called E3 ubiquitin-protein ligase CHIP, which controls the proteasomal and lysosomal pathways (21). CHIP is a component of LBs in the human brain and co-localizes with $\alpha$-synuclein and heat shock $70 \mathrm{kDa}$ protein. 
The structural domains of CHIP facilitate the mediation of $\alpha$-synuclein degradation through the proteasomal pathway (via its tetratricopeptide repeat structural domain) and through the lysosomal pathway (via its U-box domain). Numerous studies have demonstrated that proteasome inhibitors are able to induce dopaminergic neuronal cell death and the formation of intracellular inclusion bodies $(22,23)$. It has also been found that the soluble oligomeric formation of $\alpha$-synuclein protein can be degraded by the lysosomal pathway (24), and may be associated with CMA $(25,26)$.

Lactacystin is a metabolite of Streptomyces and is hydrolyzed in the body to produce an activated intermediate product, $\beta$-lactone. The activity of the $20 \mathrm{~S}$ subunit of the proteasomes can be exclusively inhibited by binding between the proteasome proteins and the $20 \mathrm{~S} \beta$-subunit (27). E64, a specific inhibitor of lysosomes, inhibits the activity of cysteine proteinases in the lysosome and affects the degradation of the substrate (28).

PC12 cells are positive in the tyrosine hydroxylase (TH) immune response, have the ability to compose and excrete dopamine and can undergo differentiation into a neuronal phenotype following induction by NGF. In the present study, NGF was utilized to induce the PC12 cells. As a result, the cell body of the PC12 cells became enlarged, the cells became polygonal, the adherent ability of the cells was enhanced and cell growth was attenuated. Consequently, these NGF-induced PC12 cells were used as the ideal neuronal dopaminergic cell model to study the pathogenesis of PD.

The present study demonstrated that, when the proteasomal and lysosomal pathway inhibitors lactacystin and E64 were incubated with the PC12 cells independently or in combination, the activity and metabolism of the PC12 cells were notably decreased, while the rate of apoptosis was increased. This phenomenon was more evident when lactacystin and E64 were incubated with PC12 cells in combination. According to the study results, the dysfunction of the proteasomal or lysosomal pathway damages the cell, and the effect of the pathway damage is synergistic.

In this study, it was observed that a low level of $\alpha$-synuclein protein aggregation occurred following the administration of the lysosomal inhibitor, while marked aggregation occurred with the proteasomal inhibitor. The highest level of aggregation occurred when the lysosomal and proteasomal inhibitors were applied in combination. A recent study has shown that the half life of the $\alpha$-synuclein protein in the monomeric form is shorter than that of the protein in the aggregated form. In mammalian cells, the short half-life protein is degraded by the proteasomal pathway and the long half-life protein is degraded by the lysosomal pathway (29).

According to the results of the present study, we speculated that the selectivity of the $\alpha$-synuclein protein degradation pathways could be associated with the half-life and form of the protein; under normal circumstance, those proteins with a short half-life existing in a soluble monomeric form would be degraded by the ubiquitin-proteasome system, while those proteins with a long half-life existing in an aggregated form would be degraded by a lysosomal pathway, in interdependent and mutual processes. Following damage to one or both of these pathways, or when the levels of $\alpha$-synuclein protein exceed the degradation ability of the pathways, $\alpha$-synuclein protein would not be able to undergo timely degradation, and the accumulation of the $\alpha$-synuclein protein would cause toxicity and lead to the degeneration and death of dopaminergic neurons. The mechanism of cell death could be associated with apoptosis, since the study results indicated that $17.29 \%$ of the $\alpha$-synuclein protein and thioflavin S double-positive cells were apoptotic. This indicated that the $\alpha$-synuclein inclusion bodies had a toxic effect on the cells, which led to cell apoptosis (30). Due to the apoptotic cell death evidenced in the substantia nigra of patients with PD $(31,32)$, it is reasonable to speculate that the inclusion bodies formed from accumulated $\alpha$-synuclein may lead to the death of dopaminergic neurons through the apoptotic pathway. In addition, it was suggested in the present study that dysfunction of the proteasomal and lysosomal pathways could play an important role in dopaminergic neuron degeneration and the process of protein accumulation and inclusion body formation. $\alpha$-synuclein linked the heredity and the environmental factors of PD.

The association between $\alpha$-synuclein degradation and the formation of LBs, as well as the understanding that $\alpha$-synuclein accumulation may be involved in the development of PD, may provide fresh insights to further understand the pathogenesis of PD. In future studies, we aim to continually focus on exploring the mechanism of $\alpha$-synuclein degradation and accumulation, in order to seek more effective methods to prevent the pathological deposition.

\section{References}

1. Ghosh A, Roy A, Liu X, et al: Selective inhibition of NF-kappaB activation prevents dopaminergic neuronal loss in a mouse model of Parkinson's disease. Proc Natl Acad Sci USA 104: 18754-18759, 2007.

2. Bennett MC: The role of alpha-synuclein in neurodegenerative diseases. Pharmaco1 Ther 105: 311-331, 2005.

3. Bisaglia M, Mammi S and Bubacco L: Structural insights on physiological functions and pathological effects and alpha-synuclein. FASEB J 23: 329-340, 2009.

4. Nemani VM, Lu W, Berge V, et al: Increased expression of alpha-synuclein reduces neurotransmitter release by inhibiting synaptic vesicle reclustering after endocytosis. Neuron 65: 66-79, 2010.

5. Xu J, Kao SY, Lee FJ, Song W, Jin LW and Yankner BA: Dopamine-dependent neurotoxicity of $\alpha$-synuclein: A mechanism for selective neurodegeneration in Parkinson disease. Nat Med 8: 600-606, 2002.

6. Yamanka K, Saito Y, Yamamori T, Urano Y and Noguchi N: 24(S)-hydroxycholesterol induces neuronal cell death through necroptosis, a form of programmed necrosis. J Biol Chem 286: 24666-34673, 2011.

7. Beyer K and Ariza A: Protein aggregation mechanism in synucleinopathies: Commonalities and differences. J Neuropathol Exp Neurol 66: 965-974, 2007.

8. Hu X, Zhang H, Zhang Y, et al: Differential protein profile of PC12 cells exposed to proteasomal inhibitor lactacystin. Neurosci Lett 575: 25-30, 2014.

9. Ryu EJ, Angelastro JM and Greene LA: Analysis of gene expression changes in a cellular model of Parkinson disease. Neurobiol Dis 18: 54-74, 2005.

10. McNaught KS, Shashidharan P, Perl DP, Jenner P and Olanow CW: Aggresome-related biogenesis of Lewy bodies. Eur J Neurosci 16: 2136-2148, 2002.

11. Pouplana S, Espargaro A, Galdeano C, et al: Thioflavin-S staining of bacterial inclusion bodies for the fast, simple, and inexpensive screening of amyloid aggregation inhibitors. Curr Med Chem 21: 1152-1159, 2014.

12. Maroteaux L, Campanelli JT and Scheller RH: Synuclein: A neuron-specific protein localized to the nucleus and presynaptic nerve terminal. J Neurosci 8: 2804-2815, 1988. 
13. Jo E, McLaurin J, Yip CM, St George-Hyslop P and Fraser PE: alpha-Synuclein membrane interactions and lipid specificity. J Biol Chem 275: 34328-34334, 2000.

14. McNaught KS, Björklund LM, Belizaire R, Isacson O, Jenner P and Olanow CW: Proteasome inhibition causes nigral degeneration with inclusion bodies in rats. Neuroreport 13: 1437-1441, 2002.

15. Banerjee K, Munshi S, Sen O, Pramanik V, Roy Mukherjee T and Chakrabarti S: Dopamine cytotoxicity involves both oxidative and nonoxidative pathways in SH-SY5Y cells: Potential role of alpha-synuclein overexpression and proteasomal inhibition in the etiopathogenesis of Parkinson's disease. Parkinsons Dis 2014: 878935, 2014.

16. Bucciantini M, Giannoni E, Chiti F, et al: Inherent toxicity of aggregates implies a common mechanism for protein misfolding diseases. Nature 416: 507-511, 2002.

17. Ciechanover A: The ubiquitin-proteasome pathway: On protein death and cell life. EMBO J 17: 7151-7160, 1998.

18. Cesen MH, Pegan K, Spes A and Turk B: Lysosomal pathways to cell death and their therapeutic applications. Exp Cell Res 318 $1245-1251,2012$.

19. Boya P and Kroemer G: Lysosomal membrane permeabilization in cell death. Oncogene 27: 6434-6451, 2008.

20. Webb JL, Ravikumar B, Atkins J, Skepper JN and Rubinsztein DC: Alpha-Synuclein is degraded by both autophagy and the proteasome. J Biol Chem 278: 25009-25013, 2003.

21. Shin Y, Klucken J, Patterson C, Hyman BT and McLean PJ: The co-chaperone carboxyl terminus of Hsp70-interacting protein (CHIP) mediates alpha-synuclein degradation decisions between proteasomal and lysosomal pathways. J Biol Chem 280 : 23727-23734, 2005 .

22. Lazzeri G, Lenzi P, Busceti CL, et al: Mechanisms involved in the formation of dopamine-induced intracellular bodies within striatal neurons. J Neurochem 101: 1414-1427, 2007.
23. Jeon SM, Cheon SM, Bae HR, Kim JW and Kim SU: Selective susceptibility of human dopaminergic neural stem cells to dopamine-induced apoptosis. Exp Neurobiol 19: 155-164, 2010.

24. Lee HJ, Khoshaghideh F, Patel S and Lee SJ: Clearance of alpha-synuclein oligomeric intermediates via the lysosomal degradation pathway. J Neurosci 24: 1888-1896, 2004.

25. Cuervo AM, Stefanis L, Fredenburg R, Lansbury PT and Sulzer D: Impaired degradation of mutant alpha-synuclein by chaperone-mediated autophagy. Science 305: 1292-1295, 2004.

26. Eskelinen EL, Illert AL, Tanaka Y, Schwarzmann G, Blanz J, Von Figura K and Saftig P: Role of LAMP-2 in lysosome biogenesis and autophagy. Mol Biol Cell 13: 3355-3368, 2002.

27. Gu W and Silverman RB: Stereospecific total syntheses of proteasome inhibitor omuralide and lactacystin. J Org Chem 76: 8287-8293, 2011

28. Wijayanti MA, Sholikhah EN, Hadanu R, Jumina J, Supargiyono S and Mustofa M: Additive in vitro antiplasmodial effect of N-alkyl and N-benzyl-1,10-phenanthroline derivatives and cysteine protease inhibitor e64. Malar Res Treat 2010: 540786, 2010.

29. Mo JS, Yoon JH, Hong JA, et al: Phosphorylation of nicastrin by SGK1 leads to its degradation through lysosomal and proteasomal pathways. PLoS One 7: e37111, 2012.

30. Rideout HJ and Stefanis L: Proteasomal inhibition-induced inclusion formation and death in cortical neurons require transcription and ubiquitination. Mol Cell Neurosci 21: 223-238, 2002.

31. Anglade P, Vyas S, Javoy-Agid F, et al: Apoptosis and autophagy in nigral neurons of patients with Parkinson's disease. Histol Histopathol 12: 25-31, 1997.

32. Tain LS, Chowdhury RB, Tao RN, et al: Drosophila HtrA2 is dispensable for apoptosis but acts downstream of PINK lindependently from Parkin. Cell Death Differ 16: 1118-1125, 2009. 